\title{
Cervical cancer screening programmes and policies in 18 European countries
}

\author{
A Anttila', G Ronco ${ }^{2}$, G Clifford ${ }^{3}$, F Bray ${ }^{3}$, M Hakama ${ }^{1,3}$, M Arbyn ${ }^{4}$ and E Weiderpass ${ }^{*, 1,3,5,6}$ \\ 'The Finnish Cancer Registry, Helsinki, Finland; ${ }^{2}$ Unit of Cancer Epidemiology, CPO Piemonte, Torino, Italy; ${ }^{3}$ The International Agency for Research on \\ Cancer, Lyon France; ${ }^{4}$ Scientific Institute of Public Health, Brussels, Belgium; ${ }^{5}$ Cancer Registry of Norway, Oslo, Norway; ${ }^{6}$ Department of Medical \\ Epidemiology and Biostatistics, Karolinska Institutet, Stockholm, Sweden
}

A questionnaire survey was conducted by the Epidemiology Working Group of the European Cervical Cancer Screening Network, and the International Agency for Research on Cancer, IARC, between August and December 2003 in 35 centres in 20 European countries with reliable cervical cancer incidence and/or mortality data in databanks held at IARC and WHO. The questionnaire was completed by 28 centres from 20 countries. The final tables included information on 25 centres from 18 countries. Six countries had started screening in the 1960s, whereas 10 countries or regions had started at least a pilot programme by 2003. There were six invitational and nine partially invitational programmes, the rest employing opportunistic screening only. Recommended lifetime number of smears varied from seven to more than 50. Coverage of smear test within the recommended screening interval (usually 3 or 5 years) was above $80 \%$ in three countries. Screening registration took place in 13 programmes. Eight programmes reported the rates of screen-detected cervical cancers and precursor lesions. There was wide variation in the CIN3 detection rates. International guidelines and quality assurance protocols are useful for monitoring and evaluating screening programmes systematically. Our survey indicated that the recommendations as currently given are met in only few European countries. Health authorities need to consider stronger measures and incentives than those laid out in the current set of recommendations.

British Journal of Cancer (2004) 91, 935-94I. doi:I0.1038/sj.bjc.6602069 www.bjcancer.com

Published online 27 July 2004

(c) 2004 Cancer Research UK

Keywords: epidemiology; cervix uteri; screening; evaluation; monitoring

\section{BACKGROUND}

Organised screening programmes for cervical cancer using Pap smears have been shown to be effective in decreasing mortality and incidence from the disease (Fidler et al, 1968; Hakama and Räsänen-Virtanen, 1976; Hakama, 1982; Day, 1986; Läärä et al, 1987; Lynge, 2000). Opportunistic or nonorganised screening also decrease cervical cancer rates, although not to the extent of organised programmes (Magnus and Langmark, 1986; Lynge et al, 1989; Nieminen et al, 1999). One problem with nonorganised screening is that it may not adequately cover the population targeted, sometimes missing those at highest risk (Coleman et al, 1993a).

If clinical and diagnostic quality are not monitored and evaluated systematically, as in nonorganised screening, there are also concerns that adverse effects may become more common (Council of the EU, 2003). The goal of an organised programme, along with achieving reasonable effectiveness, is that potential adverse effects are minimised while screening-related improvements in the quality of life maximised. Overuse of services can be

*Correspondence: Dr E Weiderpass, Finnish Cancer Registry, Liisankatu 2I B, FIN-00 I70 Helsinki, Finland; E-mail: elisabete.weiderpass@cancer.fi Received 30 March 2004; revised 16 June 2004; accepted 16 June 2004; published online 27 July 2004 prevented and a complete evaluation can be implemented only within the framework of an organised programme.

The European Union (EU) currently recommends that cancer screening should only be offered on a population basis in organised screening programmes, with quality assurance at all levels (Council of the EU, 2003). There are also some more detailed recommendations describing the implementation, registration, monitoring, training, compliance, and introduction of novel tests of organised cancer screening programmes (Advisory Committee on Cancer Prevention, 2000; Sankila et al, 2000; Council of the EU, 2003). Managerial guidelines have also been published by the WHO, and there are guidelines in several areas or individual countries describing how to organise a programme.

In Europe, there are wide variations in the organisation of cervical cancer screening activities (Linos et al, ed., 2000). The present study aims to describe the main policy and organisational elements in cervical cancer screening programmes in many European countries, and compare them with the EU and other recommendations.

\section{MATERIALS AND METHODS}

The study is based on a questionnaire survey, collected in late 2003 from 20 European countries within the framework of a collaborative research project of the European Cervical Cancer Screening Network (ECCSN), funded by the Europe Against Cancer 
programme, and the International Agency for Research on Cancer (IARC), Lyon. The questionnaire survey was conducted in August-December 2003. The present report summarises the current and historical screening situation in Europe. However, as these data were also collected within the framework of interpreting long-term cervical cancer trends at a population level, only European countries or regions for which cervical cancer mortality and/or incidence data met eligibility criteria for the assessment of cervical cancer trends were included.

More specifically, countries or regions were selected according to the following criteria:

(1) Countries with mortality data available for more than 10 years (not necessarily consecutively) in the WHO mortality database up to 2000, and where 'Not Otherwise Specified' uterine cancer deaths accounted for less than $25 \%$ of all uterine cancer deaths (these NOS uterine cancer deaths can be redistributed based on the age-specific proportion of registered cervix and corpus cancer deaths (Arbyn and Geys 2002; Bray et al, 2002)).

(2) Countries without mortality data meeting the above quality criteria, but for which cervical cancer incidence data of sufficient quality was available, either nationwide, or within a specific region. Criteria for data quality consisted of cancer registry-based incidence data published in at least three consecutive volumes of 'Cancer incidence in five continents' from IARC (Parkin et al, 1992, 1997, 2002).

Countries meeting criteria for mortality data were: the Czech Republic, Denmark, Estonia, Finland, Hungary, Iceland, Lithuania, Luxembourg, the Netherlands, Norway, Switzerland, and the UK. Countries and regions meeting criteria for incidence data were: France (regional data only, from eight regions: Bas-Rhin, Calvados, Doubs, Herault, Isére, Limousin, Somme, Tarn); Germany (Saarland only); Italy (from four regions: Florence, Parma, Ragusa, Varese, and two cities: Genova, Torino); Poland (Cracow only); Slovakia, Slovenia, Spain (from four regions: Catalonia, Granada, Murcia, Navarra), and Sweden. For countries with only regional incidence data, region-specific information on cervical cancer screening was requested.

Emphasis was placed on collecting both current and historical information on the following:

- Screening policy: Year of programme initiation; target age range of screening; screening interval for women with normal results; financial cost of the smear to the women;

- Organisational issues: Whether all women in the target population are invited, or only those without a recent smear; the manner in which women are invited (personally or otherwise); the data source from which invitations are drawn; whether invitations and visits are centrally registered on an individual basis; if there had been, historically, important changes in the screening organisation;

- Process and performance measures: Invitational and geographical coverage of the programme or policy; screening attendance; proportion of women tested at least once within the recommended interval; availability of data on detection rates of histologically confirmed cancerous or precancerous findings, by severity of lesions.

We also enquired as to how estimates on screening parameters were collected and calculated in order to assess the reliability of the reported information, and we also searched for all published information on the programmes.

Different organisational definitions affect the applicability of the concept, while invitational coverage can apply only among invitational programmes. Another measure of coverage, the proportion of the target population subject to formal programme or policy (van Ballegooijen et al, 2000), was included in the tables. In addition, proportion of women tested at least once within the recommended interval was used. The latter attendance rate is a combined measure of invitational coverage and related attendance, plus noninvitational smear-taking activity.

In addition to smears taken within programmes, spontaneous smears taken outside the programme were reported by several centres. Lack of information prevented their inclusion in detail in all performance measures. For those programmes, which registered smears, proportions of women tested at least once during the recommended interval could be calculated from the register-based source. For those programmes that registered only the invitational programme, corresponding estimates were based usually on questionnaire surveys where the reliability of the information may be limited due to reporting and selection biases. Owing to the lack of information, calculations could not be carried out for some other relevant time windows, such as smears during the last 10 year period.

The 2003 survey was sent to 35 centres in 20 countries and was completed by 28 centres from 20 countries. In the returned questionnaires from Estonia, Cracow (Poland), and Somme (France), it was reported that no 'organised programme or otherwise defined screening policy for cervical cancer' existed and there were no responses to further questions on screening activities. Therefore, these countries/regions were not included in the detailed tables. All the questionnaire information was managed in a database at IARC.

\section{RESULTS}

Details of screening policy are included in Table 1, irrespective of whether organised, spontaneous, or nonspecific screening programmes were in place. Six countries (the Czech Republic, Denmark, Finland, Iceland, Luxembourg, Sweden) reported having started screening in the $1960 \mathrm{~s}$, whereas 10 other countries or regions (Hungary, Lithuania, Norway, Slovenia, Bas-Rhin, Doubs, Isere, Genova, Parma, Torino) had started at least a pilot by 2003. There were large differences in target age range and interval. Recommended lifetime number of smears varied from seven (Finland, Lithuania, Netherlands, Isere) to more than 50 (Luxembourg, Germany).

The cost covered by the screened women varied widely. In most of the regions ( 17 out of $25 ; 68 \%$ ), screening was free of charge for the women but in several programmes payment practices varied even within the programme, depending on the area or mode of screening activity.

Six countries/regions had invitational programmes (Finland, Hungary, the Netherlands, Isére, Parma, Torino), whereas nine countries/regions (Denmark, Iceland, Norway, Slovenia, Swdeden, United Kingdom, Bas-Rhin, Doubs, Florence) invited only those women who had not had a smear (usually opportunistic) recently or within the recommended interval (Table 2). The other regions did not invite women, but screening was offered mainly at the occasion of a visit to a general practitioner or gynaecologist.

All of the six fully invitational programmes also had a centralised national or regional screening registration database arranged on an individual basis. Five of these registers included only the invitational programme and one (the Netherlands) included any smears. From among the programmes with partial invitations, two programmes (Denmark, Sweden) did not have a centralised national registration unit. The rest of the national programmes with a partial invitational activity reported a central national registration system, and these registers aimed to include all smears, whether taken after invitation or otherwise. Of the 10 countries/regions with opportunistic screening policies, eight were without screening registration and two had partial registration.

Smear test coverage above $80 \%$ of the target population during the recommended screening interval was reported in three national 
Table I Screening policy in the 18 European countries

\begin{tabular}{|c|c|c|c|c|c|}
\hline Country/region & $\begin{array}{l}\text { Onset of screening } \\
\text { programme or policy }\end{array}$ & $\begin{array}{l}\text { Age range targeted } \\
\text { (since year) }\end{array}$ & $\begin{array}{l}\text { Recommended screening } \\
\text { interval }\end{array}$ & $\begin{array}{l}\text { Charge of smear for } \\
\text { the women }\end{array}$ & $\begin{array}{l}\text { Recommended } \\
\text { number of } \\
\text { lifetime smears }\end{array}$ \\
\hline Czech Republic & 1966 & Not specified (1966) & I year & Free & Not specified \\
\hline Finland & 1963 & $30-60(1993)$ & 5 years & Free & 7 \\
\hline Hungary & 2003, pilot 1997 & $25-65(1997)$ & 3 years, after one negative smear & Free & 15 \\
\hline Lithuania & 2001 & $30-60(200 \mid)$ & 5 years & $\begin{array}{l}\text { Free or partial } \\
\text { contribution ( } 5 \text { euro) }\end{array}$ & 7 \\
\hline Luxembourg & 1962 & $15+(1990)$ & I year & Free & $\sim 70$ \\
\hline Netherlands & 1980 & $30-60(1996)$ & 5 years & Free & 7 \\
\hline Norway & $\begin{array}{l}\text { 1995, pilot } 1992 \text { (programme } \\
\text { in one county in 1959-1977) }\end{array}$ & $25-69(1992)$ & 3 years & Partial contribution & 15 \\
\hline Slovakia & - (intention) & $25-64(-)$ & 3 years & Free & 14 \\
\hline Switzerland & No data & $18-69(-)$ & 3 years & Partial contribution & 18 \\
\hline & 1988 & $\begin{array}{l}20-64 \text { (1988, under } \\
\text { review) }\end{array}$ & $\begin{array}{l}3-5 \text { years (currently } 3 \text { years in ages } \\
25-49 \text { years and } 5 \text { years in ages } \\
50-64 \text { years) }\end{array}$ & Free & $10-17(12)$ \\
\hline \multicolumn{6}{|c|}{ - } \\
\hline Bas-Rhin & 1994 & $25-65(1990)$ & 3 years & Partial contribution & 14 \\
\hline Doubs & 1993 & $20-65(1993)$ & $\begin{array}{l}3 \text { years (after two normal exams } \\
\text { with I year interval) }\end{array}$ & Reimbursement & 17 \\
\hline Isére & 1990 & $50-69(1990)$ & 3 years & Free & 7 \\
\hline \multicolumn{6}{|l|}{ Germany } \\
\hline \multicolumn{6}{|l|}{ Italy } \\
\hline Florence & 1982 & $25-64(1995)$ & 3 years & Free & 14 \\
\hline Genova & 1992 & $25-64(1992)$ & 3 years & Free & 14 \\
\hline
\end{tabular}

programmes (Finland, Sweden, UK); and the smear coverage was $75-80 \%$ in three countries (Denmark, Iceland, the Netherlands).

A total of 11 programmes reported collection of information on histologically confirmed lesions (Table 2). Six of these programmes reported detection rates by grade of the histological finding (Finland, Iceland, Norway, Bas-Rhin, Florence, Torino) and one country (the Netherlands) did not separate invasive cancers from the CIN3 (Table 3). Histological information was also reported from Catalonia, a region with opportunistic activity only. No published routine monitoring information was available for other programmes. There was a wide variability in the rates between the seven programmes from 0.008 to $0.04 \%$ for invasive cancer, from 0.06 to $0.50 \%$ for CIN3, and from 0.12 to $0.8 \%$ for CIN1-2. CIN3: invasive cancer detection ratios ranged from 1.5 to 12 .

\section{DISCUSSION}

The European Union has currently recommended that cancer screening should only be offered on a population basis in organised screening programmes, with quality assurance at all levels (Council of the EU, 2003). There are also more detailed recommendations that are valuable in relation to organisational aspects (Advisory Committee on Cancer Prevention, 2000; Council of the EU, 2003). The present questionnaire-based survey indicates that these recommendations are met in only a few European countries.

The most serious inadequacies relate, according to our survey, to: (1) low or inadequate coverage of the screening test within the populations targeted; (2) shortcomings in routine registration, evaluation, and monitoring; and (3) excessive numbers of lifetime smears recommended. There also exist relatively short screening intervals that are not justified as present knowledge of the natural history of cervical cancer, particularly on the duration of precancerous stage. Such aspects as payment strategies, possibly affecting attendance, varied greatly, indicating a potential for inequality.

Incidence and mortality rates from cervical cancer can be decreased by at least $80 \%$ by means of screening. This has been shown from follow-up studies of women screened negative (Day, 1986), cohort follow-up studies among screened women (Fidler et al, 1968; Hakama and Räsänen-Virtanen, 1976; Lynge, 2000), and population-based follow-up studies (Hakama 1982; Day, 1986; 
Table 2 Organisation characteristics in screening for cervical cancer in the 18 European countries

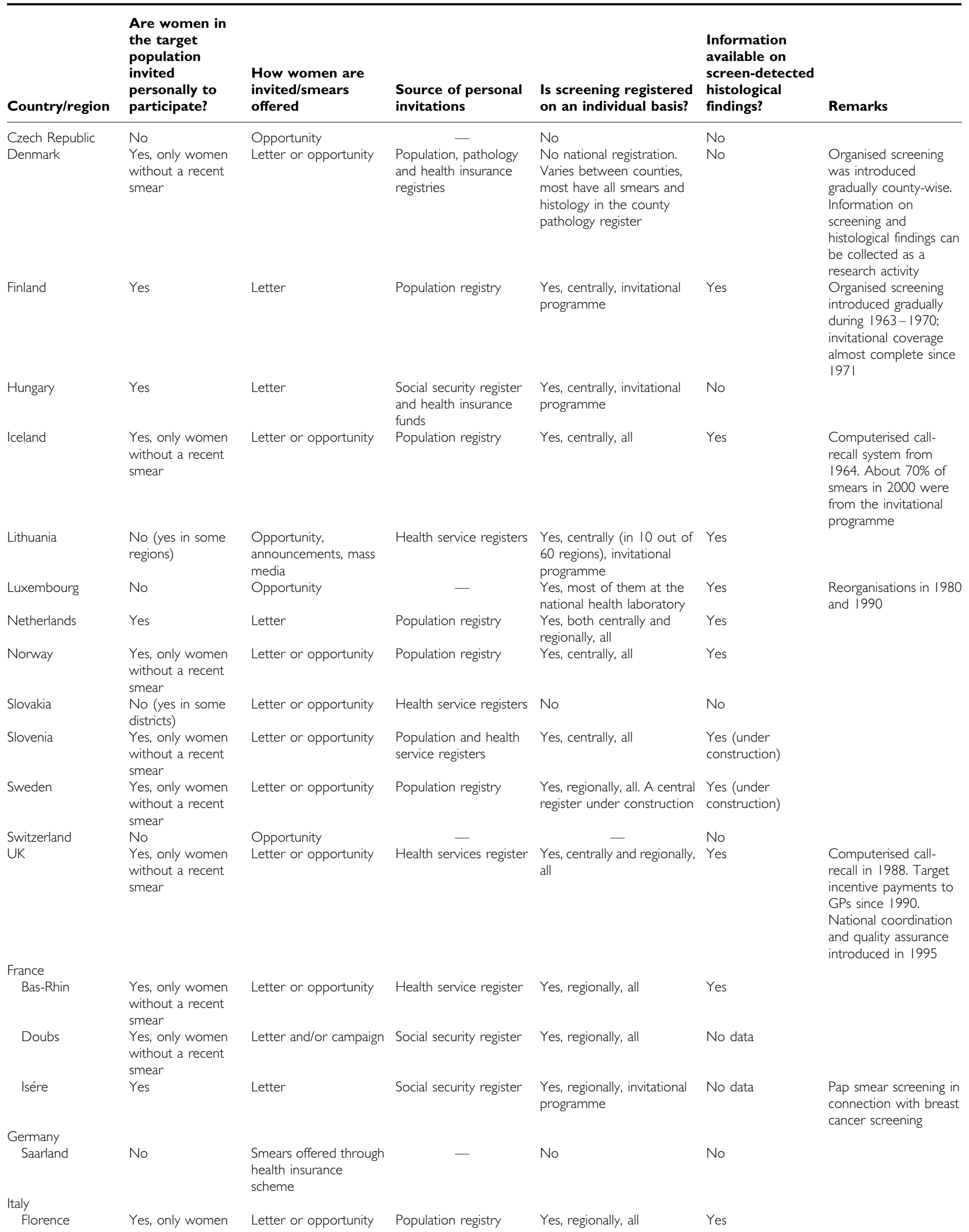


Table 2 (Continued)

\begin{tabular}{|c|c|c|c|c|c|c|}
\hline Country/region & $\begin{array}{l}\text { Are women in } \\
\text { the target } \\
\text { population } \\
\text { invited } \\
\text { personally to } \\
\text { participate? }\end{array}$ & $\begin{array}{l}\text { How women are } \\
\text { invited/smears } \\
\text { offered }\end{array}$ & $\begin{array}{l}\text { Source of personal } \\
\text { invitations }\end{array}$ & $\begin{array}{l}\text { Is screening registered } \\
\text { on an individual basis? }\end{array}$ & $\begin{array}{l}\text { Information } \\
\text { available on } \\
\text { screen-detected } \\
\text { histological } \\
\text { findings? }\end{array}$ & Remarks \\
\hline & $\begin{array}{l}\text { without a recent } \\
\text { smear }\end{array}$ & & & & & \\
\hline Ragusa & No & Opportunity & - & No & No & \\
\hline Torino & Yes & Letter & Population registry & $\begin{array}{l}\text { Yes, regionally, invitational } \\
\text { programme }\end{array}$ & Yes & \\
\hline Varese & No & Opportunity & - & No & No & $\begin{array}{l}\text { Screening campaigns in } \\
\text { the past within part of } \\
\text { the area }\end{array}$ \\
\hline
\end{tabular}

Table 3 Process and performance values in screening for cervical cancer in the 18 European countries

Detection rate $(\%)$

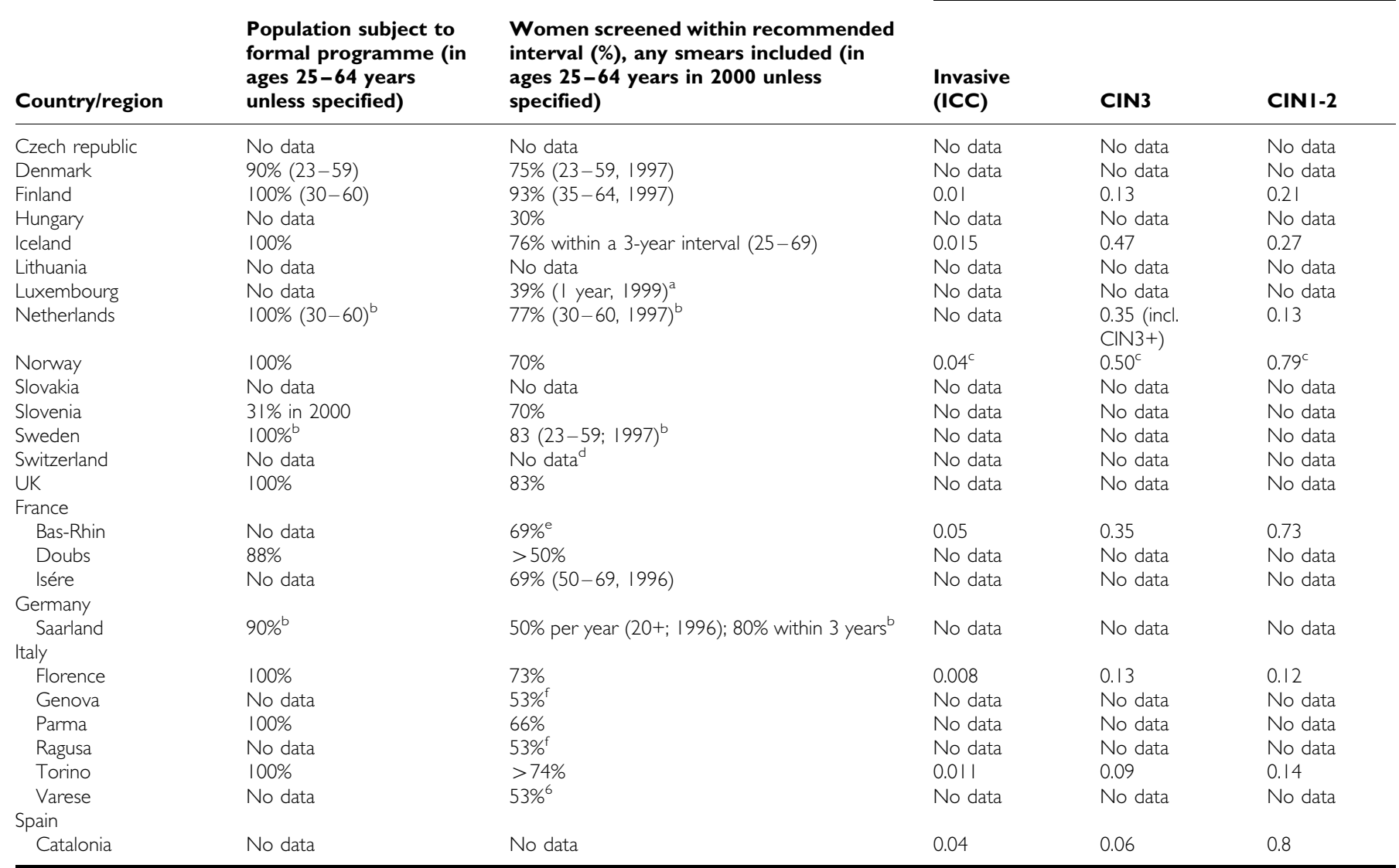

${ }^{a}$ From Scheiden et al (2000). ${ }^{b}$ From Van Ballegooijen et al (2000); whole Germany. In 1998, from The Cancer Registry of Norway (200I). ${ }^{\text {8 } 80 \% ~ e v e r-s c r e e n e d ~(I 8-75 ; ~ I 997) . ~}$ eFrom Schaffer et al (2000). fNo regional data. Italian national estimate 1999/2000.

Läärä et al, 1987). Declines of this order have been observed in Canada (British Columbia) (Anderson et al, 1988) and in Finland and Iceland (Läärä et al, 1987; Sigurdsson, 1999; Anttila and Läärä, 2000). In the other Nordic countries, decreases of between 40 and $60 \%$ have been reported (Sigurdsson, 1999), while the reduction tends to be of a somewhat lower order of magnitude in other regions and countries (Coleman et al, 1993b; Beral et al, 1994). Information is variable and often very limited, however, concerning the screening activities or incidence or death rates before the assumed time that screening started. These data as well as the 
current estimates of cervical cancer in Europe (Bray et al, 2002) suggest that meaningful additional decreases in the cervical cancer rates are still possible. It is important therefore to utilise the available data continually to monitor cervical incidence and mortality rates in these populations.

The current data were obtained from areas covered by longstanding cancer registries. Therefore, they may not be representative of the entire European situation. Frequently there is a link between pilot programmes for cervical cancer screening and cancer registration, given the utility of the latter using planning and screening evaluation. For example in France, all three existing regional programmes were in areas with a cancer registry considered to satisfy minimal quality assurance prerequisites. The study may thus overestimate the presence of organised programmes.

The reported CIN3 detection rates varied eight-fold. This can be expected to result in $t$ differences in related treatment rates. These differences are apparently not explained by differential screening intervals or age ranges. Variation in the background risk could provide a partial explanation, but the variations in cancer to CIN3 detection ratios suggest that differential diagnostic and registration criteria may play a major role.

The disadvantages of cancer screening include: anxiety among those screened positive or treated for a lesion, complications, potential of unnecessary medical interventions (e.g. among falsepositives), overtreatment of questionable or nonprogressive abnormalities, costs incurred, longer morbidity for cases whose prognosis is unaltered, and also false reassurance that can result in delayed presentation or investigation of symptoms for persons with false-negative test results (Hakama, 1991; Bennetts et al, 1995; Lauver et al, 1999; Peters et al, 1999; Rogstad, 2002; Idestrom et al, 2003). Quality-of-life and potential adverse aspects should be included in the evaluation of the screening programmes. These also represent important aspects to be considered for any potential new screening techniques to be implemented in programmes.

\section{REFERENCES}

Advisory Committee on Cancer Prevention (2000) Recommendations on cancer screening in the European union. Advisory committee on cancer prevention. Eur J Cancer 36: 1473 - 1478

Anderson GH, Boyes DA, Benedet JL, Le Riche JC, Matisic JP, Suen KC, Worth AJ, Millner A, Bennett OM (1988) Organisation and results of the cervical cytology screening programme in British Columbia, 1955-1985. Br Med J (Clin Res Ed) 296: 975 - 978

Anttila A, Läärä E (2000) Cervix cancer: geographical correlations. In Evaluation and Monitoring of Screening Programmes, Sankila $\mathrm{R}$ Démaret E, Hakama M, Lynge E, Schouten LJ, Parkin DM, for the European Network of Cancer Registries (eds) pp 77-97, Brussels, Luxembourg: European Commission, Europe Against Cancer Programme

Arbyn M, Geys H (2002) Trend of cervical cancer mortality in Belgium (1954-1994): tentative solution for the certification problem of unspecified uterine cancer. Int J Cancer 102: 649-654

Bennetts A, Irwig L, Oldenburg B, Simpson JM, Mock P, Boyes A, Adams K, Weisberg E, Shelley J (1995) PEAPS-Q: a questionnaire to measure the psychosocial effects of having an abnormal pap smear. J Clin Epidemiol 48: $1235-1243$

Beral V, Hermon C, Munoz N, Devesa SS (1994) Cervical cancer. Cancer Surv 19-20: $265-285$

Bray F, Sankila R, Ferlay J, Parkin DM (2002) Estimates of cancer incidence and mortality in Europe in 1995. Eur J Cancer 38: $99-166$

Coleman D, Day NE, Douglas G, Farmery E, Lynge E, Philip J, Segnan N (1993a) European guidelines for quality assurance in cervical cancer screening. Eur J Cancer 29A(Suppl 4): S1-S38

Coleman MP, Esteve J, Damiecki P, Arslan A, Renard H (1993b) Trends in Cancer Incidence and Mortality, IARC Scientific publications No. 121. Lyon: IARC

Day NE (1986) The epidemiological basis for evaluating different screening policies. In Screening for Cancer of the Uterine Cervix, Hakama M, Mille
Several Eastern European countries, which had established cancer registries, were included in this questionnaire study, but most had not implemented an organised screening programme. It should be noted that mortality rates are uniformly increasing in several countries in this region (Beral et al, 1994; IARC, 2002. Whenever possible, cancer registries should be involved in the planning and monitoring of screening programmes. Availability of local resources needs to be carefully taken into account. Given limited screening resources, the programme should be started in a few age groups, with high coverage being prioritised.

In general, there are large variations in European cervical cancer screening policies and in the organisation of programmes. Limited details are available on process and performance measures, and their correlation with effectiveness is not known. In particular, registration, monitoring, and evaluation are deficient. The EU Council recommendation states that 'subsequent monitoring and data collection on the extent to which the proposed measures are working effectively need to be arranged for the next 3-year period'. Decision-makers and health-care service providers need to consider stronger measures and incentives than the current recommendations in order to deliver successful cervical cancer control in Europe.

\section{ACKNOWLEDGEMENTS}

This project was partially financed by the European Commission from the Europe Against Cancer action programme through a grant for the European Cervical Cancer Screening Network. We thank Mrs Trudy Perdrix-Thoma for assistance with the creation of the screening databases used in this study, Anja Loos (IARC) for assistance in the selection of countries and regions eligible for the study, and all the contributors. E Weiderpass is supported by grants from the Swedish Cancer Society.
AB, Day NE (eds) (IARC Scientific Publications No 76), pp 199-209, Lyon: International Agency for Research on Cancer

Fidler HK, Boyes DA, Worth AJ (1968) Cervical cancer detection in British Columbia. J Obstet Gynecol Br Commonw 75: 392-404

Hakama M (1982) Ttrends in the incidence of cervical cancer in the Nordic countries. In Trends in Cancer Incidence, Magnus K (ed) Washington: Hemisphere Publishing

Hakama M (1991) Screening. In Oxford Textbook of Public Health, 2nd edn., Vol. 3, Applications in Public Health, Holland RW, Detels R, Knox G (eds) pp 91-106, Oxford: Oxford University Press

Hakama M, Räsänen-Virtanen U (1976) Effect of a mass screening program on the risk of cervical cancer. Am J Epidemiol 103: 512 -517

Idestrom M, Milsom I, Andersson.Ellstrom A (2003) Women's experience of coping with a positive pap smear: a register-based study of women with two consecutive Pap smears reported as CIN 1. Acta Obstet Gynecol Scand 82: 756-761

International Agency for Research on Cancer (2002) IARC Handbooks of Cancer Prevention, Vol. 7. Breast Cancer Screening, Lyon: IARC

Läärä E, Day N, Hakama M (1987) Trends in mortality from cervical cancer in the Nordic countries: association with organised screening programmes. Lancet 1: 1247-1249

Lauver DR, Kruse K, Baggot A (1999) Women's uncertainties, coping, and moods regarding abnormal papanicolaou results. J Womens Health Gend Based Med 8: $1103-1112$

Linos A, Riza E, van Ballegooijen M (2000) Cervical cancer screening in European Union. Eur J Cancer 36: 2175-2265

Lynge E, Cohort studies in the evaluation of cervix cancer screening, for the European Network of Cancer Registries (2000) In Evaluation and Monitoring of Screening Programmes, Sankila R, Démaret E, Hakama M, Lynge E, Schouten LJ, Parkin DM, for the European Network of Cancer Registries (eds) pp 119-132, Brussels, Luxembourg: European Commission, Europe Against Cancer Programme 
Lynge E, Madsen M, Engholm G (1989) Effect of organised screening on incidence and mortality of cervical cancer in Denmark. Cancer Res 49: $2157-2160$

Magnus K, Langmark F (1986) Cytological mass screening in Ostfold County, Norway. In: Screening for Cancer of the Uterine Cervix, Hakama M, Miller AB, Day NE (eds) (IARC Scientific Publications No 76), pp 87 90, Lyon: International Agency for Research on Cancer

Nieminen P, Kallio M, Anttila A, Hakama M (1999) Organised versus spontaneous pap-smear screening for cervical cancer, a case control study. Int J Cancer 83: $55-58$

Parkin DM, Muir CS, Whelan SL, Gao YT, Ferlay J, Powell J (1992) Cancer Incidence in Five continents, Vol. VI, IARC Scientific Publications No. 120. Lyon France: International Agency for Research on Cancer \& International Association of Cancer Registries

Parkin DM, Whelan SL, Ferlay J, Raymond L, Young J (1997) Cancer Incidence in Five Continents Vol. VII, IARC Scientific Publications No. 143. Lyon France: International Agency for Research on Cancer \& International Association of Cancer Registries

Parkin DM, Whelan SL, Ferlay J, Teppo L, Thomas DB (2002) Cancer incidence in five continents, Vol. VIII, IARC Scientific Publications No. 155. Lyon France: International Agency for Research on Cancer \& International Association of Cancer Registries

Peters T, Somerset M, Baxter K, Wilkinson T (1999) Anxiety among women with mild dyskaryosis: a randomized trial of an educational intervention. Br J Gen Pract 49: $348-352$

\section{Appendix}

\section{Questionnaire survey in Cervical Cancer Screening in Europe: List of contributors}

The Czech Republic: Vlasta Mazankova, Czech Cancer Registry, Prague. Denmark: Elsebeth Lynge, University of Copenhagen, Copenhagen. Estonia: Mati Rahu, Estonian Cancer Registry, Tallinn. Finland: Ahti Anttila, Finnish Cancer Registry, Helsinki. France: (Bas-Rhin) Muriel Fender, Association Eve, Strassbourg; (Doubs) Muriel Fender, and Christine Bouiller, Association pour Prévention du Cancer du Col dans le Doubs; (Isère) Muriel Fender, and Annie Garnier, ODLC, Meylan; (Somme) Muriel Fender, and Nicole Raverdy, Somme Cancer Registry, Amiens. Germany: Hartwig Zeigler, Saarland Cancer Registry, Saarbrucken. Hungary: Lajos Döbrössy and Miklos Bodo, St John Hospital, Budapest.
Rogstad KE (2002) The psychological impact of abnormal cytology and colposcopy. BJOG 109: $364-368$

Sankila R, Démaret E, Hakama M, Lynge E, Schouten LJ, Parkin DM, for the European Network of Cancer Registries (2000) Evaluation and Monitoring of Screening Programmes. Brussels, Luxembourg: European Commission, Europe Against Cancer Programme

Schaffer P, Sancho-Garnier H, Fender M, Dellenbach P, Carbillet JP, Monnet E, Gauthier GP, Garnier A (2000) Cervical cancer screening in France. Eur J Cancer 36: 2215-2220

Scheiden R, Knolle U, Wagener C, Wehenkel AM, Capesius C (2000) Cervical cancer screening in Luxembourg. Eur J Cancer 36: 2240-2243

Sigurdsson K (1999) The Icelandic and Nordic cervical screening programs: trends in incidence and mortality rates through 1995. Acta Obstet Gynecol Scand 78: $478-485$

The Cancer Registry of Norway. Masseundersokelsen mot livmorhalskreft i Norge (2001) Evaluaring av programmet 1992-1998. Kreftregisterets forskningrapport $n r .1-2000$. Keftregisteret: Oslo. 74

The Council of the European Union (2003) Council recommendation of 2 December 2003 on cancer screening. Off J Eur Union 878: $34-38$

Van Ballegooijen M, van den Akker-van Marle E, Patnick J, Lynge E, Arbyn M, Anttila A, Ronco G, Dik J, Habbema D (2000) Overview of important cervical cancer screening process values in European Union (EU) countries, and tentative predictions of the corresponding effectiveness and cost-effectiveness. Eur J Cancer 36: 2177-2188

Iceland: Kristjan Sigurdsson, Icelandic Cancer Society, Reykjavik. Italy: (Genova, Ragusa, Torino, Varese) Guglielmo Ronco, CPO Piemonte, Torino; (Parma) Guglielmo Ronco, and Carlo Naldoni, Region Emilia-Romagna; (Florence) Marco Zappa, (CSPO Florence), and Guglielmo Ronco. Lithuania: Juozas Kurtinaitis, Lithuanian Cancer Registry, Vilnius. Luxembourg: Astrid Scharpantgen, Ministry of Health, Luxembourg. The Netherlands: Marjolein van Ballegooijen, Erasmus University, Rotterdam. Norway: Steinar Thoresen, Cancer Registry of Norway, Oslo. Poland: (Cracow) Jadwiga Rachtan, Cracow Cancer Registry, Cracow. Slovakia: Ivan Plesko, National Cancer Registry of Slovak Republic, Bratislava. Slovenia: Maja Zakelj, Cancer Registry of Slovenia, Ljubljana. Spain: (Catalonia) Xavier Castellsagué, Institut Catalá d'Oncologia, Barcelona. Sweden: Pär Sparen, Karolinska Institute, Stockholm. Switzerland: Felix Gurtner Bundesamt fur Sozialversicherungen, Bern. The UK: Julietta Patnick, National Health Service Cervical Screening Programme, Sheffield. 